\title{
CORRIGENDUM
}

\section{In haematopoietic SCT for acute leukemia TBI impacts on relapse but not survival: results of a multicentre observational study}

C Aristei, A Santucci, R Corvò, G Gardani, U Ricardi, G Scarzello, SM Magrini, V Donato, L Falcinelli, A Bacigalupo,

F Locatelli, F Aversa, E Barbieri and Italian TBI working group

Bone Marrow Transplantation (2013) 48, 1588; doi:10.1038/bmt.2013.183

Correction to: Bone Marrow Transplantation (2013) 48, 908-914; doi:10.1038/bmt.2013.66; published online 27 May 2013

Since the publication of this article, the authors have noticed that the following member of the Italian TBI working group, C Vidali name was misspelt. The corrected name is shown here.
The authors apologize for any inconvenience caused.

Cristiana Vidali: Radioterapia Azienda Ospedaliero-Universitaria 'Ospedali Riuniti', Trieste; Natasha Maximova: Oncoematologia Pediatrica, Istituto per I'infanzia ed Ospedale specializzato pediatrico regionale-IRCCS 'Burlo Garofolo', Trieste. 